\title{
Evaluating the New Al and Data Driven Insurance Business Models for Incumbents and Disruptors: Is there Convergence?
}

\author{
Alex Zarifis ${ }^{1[\mathrm{https}: / / \text { orcid.org/0000-0003-3103-4601] }}$, and Xusen Cheng 2[https://orcid.org/0000-0001-7614-6514] \\ ${ }^{1}$ Loughborough University, UK \\ a.zarifis@lboro.ac.uk \\ ${ }^{2}$ Renmin University of China, China \\ xusen.cheng@ruc.edu.cn
}

\begin{abstract}
Al}$ and data technologies are a catalyst for fundamental changes to insurance business models. The current upheaval is seeing some incumbent insurers trying to do the same more effectively, while others evolve to fully utilize the new capabilities and users these new technologies bring. At the same time, technologically advanced organizations from outside the sector are entering and disrupting it. Within this upheaval however, there are signs of a convergence towards an ideal and prevailing business model. This research identifies one exemplar incumbent and one disruptor and evaluates whether their models are converging and will become similar eventually. The findings support a high degree of convergence, but some differences are likely to remain even after this transitionary period. The differences identified are firstly in the evaluation of risk and secondly that traditional insurers prioritize revenue generation from what is their primary activity, while new entrants prioritize expanding their user base.
\end{abstract}

Keywords: Artificial Intelligence, Machine Learning, Business Model, Insurance.

\section{Introduction}

Several sectors of the economy are facing a digital disruption driven by technologies like Artificial Intelligence (Al), cloud computing, big data, blockchain, the Internet of Things (loT), $5 G$ networks and social media. While this digitization has been ongoing for decades, the recent enhanced capabilities of $\mathrm{Al}$ make this change faster and more fundamental [1]. Al, particularly machine learning, is used to enhance business operations and offers a step change in speed, reliability, accuracy, new insights and new capabilities. These enhancements Al offers lead to improvements in the organization's performance, profitability, revenue and customer satisfaction [2]. However, because Al and algorithms that learn are making fundamental changes to the employee roles, processes and business models of organizations, there are also challenges [3], 'known unknowns' for which answers are being pursued and 'unknown-unknowns' where the right questions are yet to be formulated. This research follows a widely used agenda for researching digital business models in information systems that suggests insights on their transformative nature as one of the three best ways to make a contribution [4].

There is a convergence of social, mobile, analytics and cloud computing [5] that is accelerated with Al. This raises the question if this wave of technologies will create a radical change in insurance. The insurance sector is widely considered to be traditional and risk averse. Insurers are not usually early adopters in technology. While it is not a low-tech 
industry, it seems to set the threshold high for a new innovation to be adopted and have a transformative impact. Therefore, it is not just a question of what the potential is for $\mathrm{Al}$ in insurance, but how and when that potential will be reached.

While the insurance sector was always knowledge intensive the increase in data through social media, loT, mobile and cloud computing means the insight possible cannot be fully reached only with humans manually. Seamless, intelligent automated processes using $\mathrm{Al}$ are needed. This increasing role of $\mathrm{Al}$ as an enabler of big data utilization removes the bottleneck of humans in the process. Humans need to be in the loop in some processes but not others. Incumbent insurers are enhancing their capabilities in Al and big data while technology companies like Alibaba, Tencent and Tesla with existing Al and big data capabilities are providing insurance. This raises the primary research question:

Are incumbent and disruptor insurance business models converging to one ideal business model?

This research first compared how ten insurers are utilizing $\mathrm{Al}$ in their current processes and how they are creating new ones. The case studies covered five incumbent insurers and five new entrants. There was one incumbent and one new entrant from each continent. These ten cases cover the world geographically and allow ecosystems and networks of interest to emerge beyond the boundaries of the organizations used as cases. From this first phase one exemplar incumbent and one disruptor were evaluated in depth with interviews to evaluate whether their models are converging and whether they will become similar after this transitionary period. The interviews were with insurance professionals and insurance consumers. A high degree of convergence was found but some differences are likely to remain even after this transitionary period. These differences are firstly in the evaluation of risk and secondly that traditional insurers prioritize revenue generation from what is their primary activity, while new entrants don't necessarily. The rest of the paper covers the literature review and methodology followed by the analysis of the two phases and finally the conclusion.

\section{Literature Review}

\subsection{Business Models, Multichannel Retail and Route to Market}

General business models that were identified at the start of the internet [6] and were relevant for many years, no longer cover the new online models and ecosystems. Researchers are therefore exploring the distribution channels used today. Distribution channels have been included in some prominent business model ontologies, [7, 8]. Fritscher and Pigneur [7] identify them as one of nine building blocks of a business model. The nine components identified are customer segments, customer relationships, distribution channels, revenue flows, value proposition, key activities, partner network, key resources and cost structure. For insurance, the evaluation of risk is the primary activity which has the largest influence on survival and prosperity. It is necessary to understand what an insurer's strategy is and how they intend their business model to operate, but it is equally important to understand how their users perceive it.

\subsection{The Relative Advantage of Each Channel}

The consumer of insurance, like other consumers, can access insurance through several channels. These include physical retail stores, online websites and mobile applications. Each channel has different characteristics and can utilize Al differently. Similarly, employees within the organization have several ways of accessing the information they need and fulfilling the processes they need to. Therefore, the relative advantage of each channel spans across consumer facing and back office processes. The application of Al and data technologies is influencing the channel, the form of interaction and subsequently the relationship. For example, an interaction by voice, utilizing natural language processing and sentiment analysis is popular with those wanting to get insurance [9]. Consumers have an 
understanding of the relative advantage of each channel across the four steps of their purchase, which are requirements determination, vendor selection, purchase and after sales service [10]. Consumers increasingly expect customized and personalized services and the channel that can achieve this best, has a significant relative advantage. In B2C insurance, this customization can be enhanced extensively by mobile applications.

\subsection{Simple and Complex Services}

The nature of the service, how complex or simple it is, influences the approach, and expectations of the consumer [10]. Related concepts are that certain services have a low involvement, while others have a high involvement [11]. In retail insurance, there are relatively simple standardized services such as vehicle insurance, and more sophisticated complicated services like health insurance. Beyond retail insurance (B2C), the complexity of the insurance service can increase substantially, but that is outside the scope of this research. This research focuses on the front and back office processes that influence the relationship between the insurer and an individual user.

\subsection{Constructs Identified and Theoretic Foundation}

The literature review identified the significance of understanding the insurers intended strategy, particularly how they evaluate risk but also how the consumers perceive it. The consumers perception is influenced by the difference between the channels of offline, 2D websites, 3D virtual worlds and mobile across the four stages of the purchase process. Furthermore, for the consumer it is important to distinguish between simple services with limited engagement and complex services with extensive engagement. Therefore, the evaluation of the influence of the new Al and data driven value chain in insurance will be framed by these constructs.

\section{Methodology}

This research applied the method of comparative case study analysis with a critical realist epistemological perspective [12]. There were two phases, the first is broad and exploratory to capture all the issues and the second is more focused and in-depth to understand them better. In phase one the case studies covered the five incumbent insurers and the five new entrants listed in table 1.

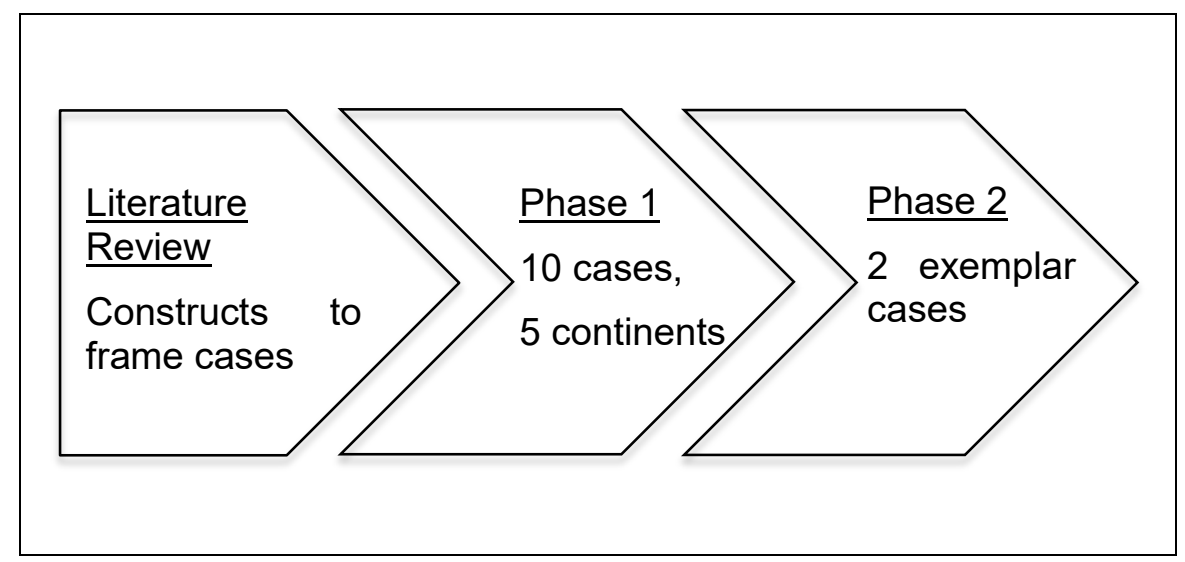

Figure 1. Research Method

There was one incumbent and one new entrant from each continent. The number was chosen for two primary reasons: Firstly, because it was the smallest number that could cover the world geographically. Secondly, the ten case studies would also allow ecosystems and 
networks of interest to emerge beyond the boundaries of the organizations used as cases. Thirdly, ten case studies were the largest number that could be presented in a research paper. The companies were selected because they embodied the characteristics of an incumbent or new entrant well. The first phase involved desk-based research covering existing research, reputable industry press like the Financial Times, Intelligent Insurer and Insurance Post, the websites and reports of the insurer, suppliers and partners.

Table 1.10 case studies by continent

\begin{tabular}{|l|l|l|}
\hline Continent & Incumbent insurers & New entrants (Disruptors) \\
\hline Europe & Bupa & Wrisk \\
America & Manulife & TESLA (Insure MyTesla) \\
Asia & Ping An & Zhong An \\
Australia & TAL Life Limited & Huddle Insurance \\
Africa & Old Mutual & Naked Insurance \\
\hline
\end{tabular}

Table 2. Demographic information of the sample group

\begin{tabular}{|c|c|c|c|}
\hline Measure & Item & TESLA & Ping An \\
\hline \multirow[t]{2}{*}{ Gender } & Female & 5 & 5 \\
\hline & Male & 5 & 5 \\
\hline \multirow[t]{5}{*}{ Age } & Under 18 & 0 & 0 \\
\hline & $18-24$ & 4 & 5 \\
\hline & $25-39$ & 3 & 4 \\
\hline & $40-59$ & 2 & 1 \\
\hline & 60 or older & 0 & 0 \\
\hline \multirow{4}{*}{$\begin{array}{l}\text { Educational } \\
\text { level }\end{array}$} & Without education level & 0 & 0 \\
\hline & High school graduate & 4 & 3 \\
\hline & University bachelor's degree & 6 & 7 \\
\hline & University master or doctorate & 0 & 0 \\
\hline \multirow{5}{*}{$\begin{array}{l}\text { Income } \\
\text { (in Euro per } \\
\text { month) }\end{array}$} & No regular income & 0 & 1 \\
\hline & $400-1200$ & 2 & 2 \\
\hline & $1201-3000$ & 7 & 6 \\
\hline & $3001-5000$ & 1 & 2 \\
\hline & $>5000$ & 0 & 0 \\
\hline
\end{tabular}

After the initial evaluation of 10 cases, 2 exemplar cases were selected for empirical data collection and in-depth analysis. For the two exemplar cases TESLA and Ping An, ten interviews were carried out for each of them. The interview participants were two managers in the companies and eight consumers. The constructs chosen to frame the business models covered both internal processes and the consumers beliefs, so interviews needed to be 
carried out with both employees and consumers. From each company one manager involved in technology implementation and one in marketing and sales were interviewed. The participants that were consumers of insurance had purchased services from one of the two companies. This was a requirement to participate.

\section{Analysis}

The desk-based research of the 10 insurers identified that $\mathrm{Al}$ and data technologies are adopted at two different speeds. Those adopting the technologies gradually have two approaches: The first is to focus and cover a smaller part of the insurance value chain, reducing cost so that their services are appealing to an ecosystem or platform like Comparethemarket.com. An example of an organization doing this effectively with some of its services is AVIVA. The second approach is to keep the same business model and use Al and data to intelligently automate and improve efficiency. An example of an organization doing this effectively with some of its services is TAL Life Limited. The insurers that are adopting $\mathrm{Al}$ and data technologies faster and more extensively are transforming their business model to fully utilize these technologies. An example of incumbent insurers changing their business model for these reasons are BUPA Health Insurance, Manulife and Ping An. An example of new disrupting insurers changing their business model for these reasons are TESLA, Wrisk and Zhong An. For the second phase of the analysis, 20 interviews were implemented with TESLA and Ping An managers and consumers.

\subsection{Strategy, Simple and Complex Services and Revenue}

The nature of the service, how simple or complex it is, influences the approach and expectations of the consumer [10]. Ping An offers both complex and simple, B2B and B2C, insurance services. They use big data and Al to understand the customers better based on the data collected on them and improve customization and satisfaction. They use this superior understanding to cross sell, create new services and gain new customers. Al driven claims processing is implemented in the Ping An Auto Insurance Smart Claim App (via Ping An), further improving customization.

Al is used for complicated claims such as a claim on the Hong Kong, Zhuhai and Macau bridge where three different insurance covers are required as there are three different jurisdictions with different insurance regulation. They also use the Voiceprint recognition system which is a facial recognition system that identifies their customers. This improves security and efficiency. One interviewee told us 'we use Al to automate administrative tasks, evaluate claims and interact with voice recognition...', '...we want to understand them (consumers) better than anyone (competitors)...'. While chatbots and natural language processing are ubiquitous in insurance now, the insurers with more and better data can train their algorithms better for both the insight and interaction.

TESLA only offers simple B2C services that can be implemented using current technologies, data and regulation. Providing insurance is not a priority in terms of revenue but complementary to their products. New innovations like self-driving cars face hurdles including insurance so having some capabilities in insurance can overcome these barriers. TESLA takes a proactive approach in shaping the insurance their cars need and collaborates with traditional insurers to deliver it in different countries. One interviewee stated: '... we spend alot of time on insurance and regulation for our self-driving cars...'.

\subsection{Risk Estimation for Underwriting and Claims Payout}

Insurers primarily add value by identifying and analyzing risk. In addition to the risks created by the person being insured there are also risks from medical malpractice, cyberthreats and viruses. It was found that the risk estimation that informed the underwriting was one of the major differences between the incumbent insurers and the technology companies entering insurance. Ping An had information of high relevance, quality and reliability on its consumers 
but this information was not updated regularly in the past: 'We have the age, education, profession, income, previous claims...we can underwrite the claim with the risk profile we want...', '...our data is more accurate than others (data) because we have taken it for decades...we can avoid premium leakage better'.

The ability of $\mathrm{Al}$ to process structured, semi-structured or unstructured datasets also improves the detection and reduction of fraud such as subrogation and multiple unlawful claims: '...it (Al) finds discrepancies by bringing together diverse data including travel information...one fraud claim stopped because the person was abroad (at the time they claimed they had an accident)'.

TESLA uses the data from cameras, and other sensors in their vehicles. Currently this data is aggregated and used in an anonymous way but in the future, it could be used to reward or punish drivers based on how they drive. When an accident happens, TESLA has extensive information on how the driver and the technology performed. Unlike traditional insurers, TESLA can proactively reduce risk by improving their hardware and software. Software updates can be delivered to all TESLA vehicles automatically. Therefore, real time data and close to real time, proactive, risk reduction influence the way risk shapes underwriting, repair cost payouts and the vehicles. One manager at Tesla stated: 'When we first updated all our cars at the push of the button this surprised a-lot of people in the industry...', 'If you look at the Cybertruck it has security features based on our experience, we did not put them in for the insurance but it will keep people safe and reduce claims...'. The security features include autopilot, stability control, anti-theft systems and bullet-resistant steel. However, as TESLA's better understanding of risk only applies to their vehicles, they may not expand beyond insuring their own vehicles.

\subsection{Engagement and Relationship with the User Across Different Channels}

While it is important to understand the intentions of insurers, it is also important to understand how their services are perceived by the consumer. The interactions and relationships between the insurer and the consumer are more frequent and nuanced than in the past. The logic behind the decision Al makes is not always transparent so this increases ambiguity.

The relative advantage of each channel for the consumer: Ping An is an incumbent insurer that offers the full range of insurance services across several distribution channels. They attempt to fully utilize new technologies by having several business models in parallel. They offer several services directly and they also have alliances with technology companies. An example of this is Zhong An, a partnership between Ping An, Alibaba and Tencent. With Ping An's original model, the engagement with the user was not frequent and did not allow for real time data collection. The partnerships with technology companies increase this engagement. In their traditional model the human interaction with the user is during sales, underwriting, post-sales support and claims management. In the new services there is increased use of chatbots and analysis of behavioral data. For example, one interviewee stated: '...there are some relationships surprise you. How long people take to fill the form in the app is linked to how risky they are...'.

Al and data technologies offer several benefits to the interaction with the user. These include (1) better automated interaction including facial recognition and sentiment analysis through the user's voice, (2) fast offers, often under 60 seconds, (3) quicker claim processing with automated features such as $\mathrm{Al}$ evaluating damage from pictures, (4) more organized interactions with better scheduling of meetings, (5) new services such as the consumer paying according to the distance travelled, (6) adapting to local conditions and regulations such as applying adaptive pricing only where it is allowed. One interviewee emphasized the importance of the interaction and how decisive this can be '...there are apps that list all the insurers... my friends like them...they are quick... but I use this one (Ping An)'. 
Table 3. Incumbent insurers and tech companies Al driven business models

\begin{tabular}{|c|c|c|}
\hline Difference & Incumbent Insurer & Tech company offering insurance \\
\hline \multirow{3}{*}{$\begin{array}{l}\text { Service } \\
\text { complexity and } \\
\text { revenue }\end{array}$} & Complex and simple service, & \multirow{3}{*}{$\begin{array}{l}\text { Simple standardised B2C services } \\
\text { Revenue not a priority but } \\
\text { complementary to their products }\end{array}$} \\
\hline & B2B and B2C service & \\
\hline & $\begin{array}{l}\text { Understand the consumers } \\
\text { better, } \\
\text { improve } \\
\text { customization } \\
\text { satisfaction of cover and } \\
\text { interaction }\end{array}$ & \\
\hline \multirow[t]{2}{*}{$\begin{array}{l}\text { Risk estimation } \\
\text { and claims } \\
\text { payout }\end{array}$} & \multirow[t]{2}{*}{$\begin{array}{l}\text { Information of a high } \\
\text { relevance, quality and } \\
\text { reliability, but this information } \\
\text { is not always updated } \\
\text { regularly }\end{array}$} & $\begin{array}{l}\text { Real time information on behaviour } \\
\text { Proactively influence behaviour (e.g. } \\
\text { premium changes based on driving } \\
\text { behaviour) }\end{array}$ \\
\hline & & $\begin{array}{l}\text { Proactively reduce risk (e.g. warning } \\
\text { or software update) }\end{array}$ \\
\hline \multirow[t]{3}{*}{$\begin{array}{l}\text { Engagement } \\
\text { with the user }\end{array}$} & \multirow{2}{*}{$\begin{array}{l}\text { Several business models in } \\
\text { parallel to utilize different } \\
\text { technologies } \\
\text { Alliance with tech companies } \\
\text { to access their user base }\end{array}$} & $\begin{array}{l}\text { Bundle insurance with existing } \\
\text { services }\end{array}$ \\
\hline & & $\begin{array}{l}\text { Remove the hurdle of insurance both } \\
\text { for the organization and the consumer }\end{array}$ \\
\hline & $\begin{array}{l}\text { to access their user base } \\
\text { Benefits to the interaction } \\
\text { with the user: Better } \\
\text { automated interaction, fast } \\
\text { offers, quicker claim } \\
\text { processing, better } \\
\text { scheduling of meetings, new } \\
\text { services, adapting to local } \\
\text { conditions and regulations }\end{array}$ & $\begin{array}{l}\text { Use existing access to user data so } \\
\text { no additional privacy concerns }\end{array}$ \\
\hline
\end{tabular}

There is an effort by this insurer to be proactive and promote a healthy lifestyle. This can be basic, offering advice and fitness trackers. It is also more advanced offering remote healthcare technology with an application that enables virtual consultations with Al powered virtual doctors. Prescriptions are provided within the application. The proactive effort reduces the risk of health problems and brings in new information to further reduce risk.

TESLA engages with consumers and makes their vehicles available for purchase both online and offline. When ordering a vehicle, a quote is given either directly from TESLA or its partners. While a TESLA is a luxury vehicle, consumers prioritized the price and simplicity of the insurance when making a decision: '... we saved $20-30 \%$ taking the insurance out directly form TESLA...'. Most interviewees did not have serious concerns over their data being used as this was already happening because they were using the vehicle: '...I love TESLA for the technology so why not use it for insurance too....

Some comments from users of both insurers showed that $\mathrm{Al}$ and data technologies can also strain the relationship and raise privacy, trust and ethical concerns. As the role of $\mathrm{Al}$ increases shifting from a tool augmenting human intelligence, to an automated insurance process without direct human involvement, some consumers are concerned about the lack of transparency and empathy: 'I don't want to talk to a machine about problems, where is the information going...', '...when I am waiting I think my internet my phone is stuck or hacking...'. Some interviewees felt the information asymmetry was increasing as their intelligence and knowledge could not compete with Al: '... is my driving good I do not know, 
maybe they have a different idea about how someone should drive...'. One interviewee referred to requests for additional information compared to what was needed in the past as '...mission creep...' suggesting the insurer is expanding their role over the years.

\section{Findings}

This research answers the call to explore the transformative nature of digital business models in information systems [4] which is particularly pertinent in insurance now. Furthermore, this research follows that call and takes into account the increasing and multifaceted influence of the user and how new ICT create value and shape the business model structure and purpose [1,4].

\subsection{How Al and Data Technologies are Changing Insurance Models}

The first stage focuses on efficiency and replacing an existing process with Al. Once an existing process has been replaced by $\mathrm{Al}$, expanding the use of $\mathrm{Al}$ is easier because machine learning can learn quickly. For example, once the Al supported virtual assistant is operating, it is easier for the virtual assistant to sell new, additional products and services.

While most large incumbent insurers are active in several countries and need to adapt their Al implementation to different regulations, many of the disruptors focus on one market at a time, keeping the simplicity of implementation low. The approach of the disruptors avoids many of the challenges to Al implementation identified such as the need to have a deep understanding of all the business processes [2]. This research supports previous findings that insurers are adapting their business models to counter competition from other markets [13].

The startups offered simple services in a fully automated way with the help of Al. The incumbents also offered some of their simpler services in this way. More complex services were supported with $\mathrm{Al}$ and data technologies but in most cases an expert made the final decision. An example of this are the audits for fraud, where the Al identifies unusual patters and cases for an expert to evaluate. While it is easy to find examples of simple and complex services in insurance, it is not easy to know where exactly to draw the line to separate all insurance services into simple and fully automatable, or complex. This is however an important question facing insurers. An example to illustrate this, is Manulife allowing its automated Al supported underwriter to underwrite life insurance from 18 to 45 , which is considered easier and less risky to evaluate compared to older ages.

The consumer's expectations are expanding in the insurance sector. The convenience, flexibility and customization the consumer receives from other sectors such as banking is now expected in insurance also. This 'pull' from the consumer is met by the incumbents and the new entrants using mobile applications, Al and APIs to the necessary data outside the organization. Several of the startups do not offer their services offline. Furthermore, some steps that speed up the process need mobile applications and their functionalities such as cameras, GPS and verification by sending a text. Therefore, it can be concluded that the mobile channel currently amplifies the capabilities offered by Al best.

\subsection{Al and Data Technology Insurance Models of Incumbents and Disruptors}

$\mathrm{Al}$ is changing the insurance value chain causing upheaval, as illustrated in figure 2 . There are several signs of convergence between the models of incumbents and disruptors. Firstly, there is convergence in technologies such as, for example, the use of chatbots and loT. Secondly there is a convergence in processes, for example the interaction with the consumer. Thirdly there is convergence in the strategy on costs and pricing, for example insurers like AVIVA focus on cost cutting to compete with incumbents like WRISK, Huddle Insurance and Naked Insurance. There are however two areas where there seems to be a 
limit on the convergence that seems to suggest the business models of the incumbent and the disruptor will remain distinct:

(1) Evaluating risk: Al and data technologies are changing the way risk is evaluated by an insurer. These new ways of using data and technology to assess risk in turn generate new insurance services. This is true for both forward looking incumbents and disruptors. Incumbents like Ping An are creating new services from the new data but they are also creating new services to gain new data.

For disruptors like TESLA risk is calculated in three ways: Firstly, data is collected from the cameras and sensors in the vehicle providing insight on real time behavior both at the individual and aggregate level. Secondly, broader analysis of individuals with hundreds of variables is implemented and new algorithms that evaluate risk accurately are pursued. Thirdly, the impact on risk of the new technologies is constantly monitored and, in some cases, influenced.

(2) Cost of attracting the user and profitability: Access to user data through new technologies. The technology company offering insurance like TESLA have some advantages in terms of the cost of attracting new consumers and the profits they generate. While the incumbent insurer must spend on marketing to attract consumers to their insurance services the technology company uses existing users. Furthermore, while the insurer is dependent on their revenues from insurance services the technology company can draw profits from other services and provide insurance without any profit.

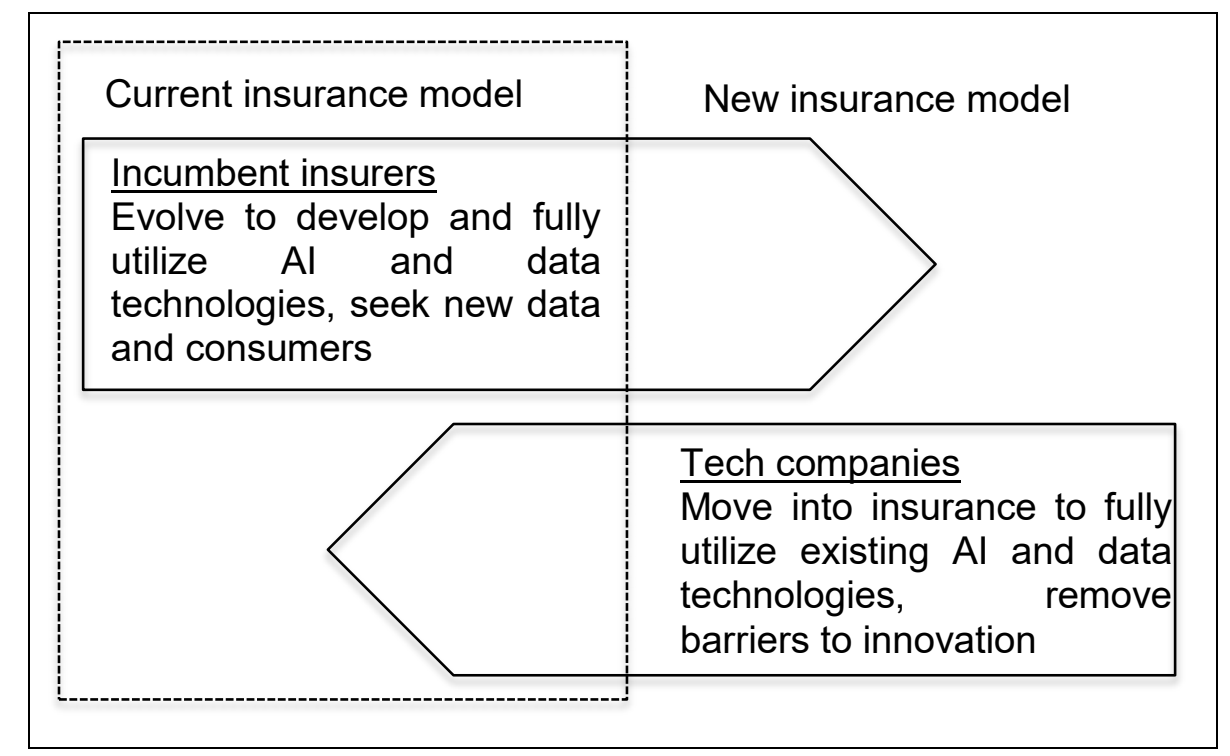

Figure 2. Partial convergence of incumbent and disrupting insurers

\section{Conclusion}

Al and data technologies are acting as a catalyst for broad changes in insurance. This research identified and evaluated two exemplar cases of an incumbent and disrupter creating business models to fully utilize these technologies. A comparative case study analysis explored these changes by interviewing insurance professionals and consumers. While there was some convergence between the two models it is not expected that they will merge into one after the transitionary period. This is because, despite the convergence, the two models have some distinct competitive advantages. While the incumbents no longer monopolize the capability of providing insurance, they still have the existing user base and use it to evaluate risk. Technology companies that offer insurance now, have their own forms of engagement with their users, use different methods to evaluate risk due to their access to real time data, 
and do not seem to prioritize generating revenue but instead utilize insurance to increase their user base, overcome barriers and reduce the overall cost of their products and services.

The limitation of this research is that despite the care taken to choose two representative cases to study, other cases may have differences. Future research can test the findings with additional in-depth case studies of incumbents and disruptors from across the world. It may also be beneficial to have a longitudinal study to further verify the convergence of the insurance business models that fully utilize Al and data technologies.

Statement on competing interests: The authors declare that there is no conflict of interest.

\section{References}

1. Alt, R., Leimeister, J.M., Priemuth, T., Sachse, S., Urbach, N., Wunderlich, N.: Software-Defined Business: Implications for IT Management. Bus. Inf. Syst. Eng. 62, 609-621 (2020).

2. Tarafdar, M., Beath, C.M., Ross, J.W.: Using Al to Enhance Business Operations. MIT Sloan Manag. Rev. 60, 10 (2019).

3. Faraj, S., Pachidi, S., Sayegh, K.: Working and organizing in the age of the learning algorithm. Inf. Organ. 28, 62-70 (2018).

4. Veit, D., Clemons, E., Benlian, A., Buxmann, P., Hess, T., Kundisch, D., Leimeister, J.M., Loos, P., Spann, M.: Business models: An information systems research agenda. Bus. Inf. Syst. Eng. 6, 45-53 (2014).

5. Legner, C., Eymann, T., Hess, T., Matt, C., Böhmann, T., Drews, P., Mädche, A., Urbach, N., Ahlemann, F.: Digitalization: Opportunity and Challenge for the Business and Information Systems Engineering Community. Bus. Inf. Syst. Eng. 59, 301-308 (2017).

6. Timmers, P.: Business Models for Electronic Markets. Electron. Mark. 8, 3-8 (1998).

7. Fritscher, B., Pigneur, Y.: Supporting business model modelling: A compromise between creativity and constraints. Lect. Notes Comput. Sci. (including Subser. Lect. Notes Artif. Intell. Lect. Notes Bioinformatics). 5963 LNCS, 28-43 (2010).

8. Oliveira, M.A.-Y., Ferreira, J.J.P.: Book Review: Business Model Generation: A handbook for visionaries, game changers and challengers. John Wiley and Sons, Hoboken, New Jersey (2010).

9. Maull, R., Collomosse, J., Brewer, S., Bordon, A., Jones, K., Breeze, J.: Taking control: Artificial intelligence and insurance. (2019).

10. Choudhury, V., Karahanna, E.: The Relative Advantage of Electronic Channels: A Multidimensional View. Manag. Inf. Syst. Q. 32, 179-200 (2008).

11. Zaichkowsky, J.L.: Measuring the Involvement Construct. J. Consum. Res. 12, 341352 (1985).

12. Eisenhardt, K.M.: Building Theories from Case Study Research. Acad. Manag. Rev. 14, 532-550 (1989).

13. Eling, M., Lehmann, M.: The Impact of Digitalization on the Insurance Value Chain and the Insurability of Risks. Geneva Pap. Risk Insur. Issues Pract. 43, 359-396 (2018). 